\title{
Perdas e desperdícios de alimentos: reflexões sobre o atual cenário brasileiro
}

\section{Food losses and waste: reflections on the current brazilian scenario}

\author{
Karin Luise dos Santos ${ }^{1 *}$ (1), Jenifer Panizzon ${ }^{1,2}$, Manuela Machado Cenci ${ }^{3}$, \\ Gabriel Grabowski ${ }^{1}$, Vanusca Dalosto Jahno ${ }^{1}$
}

${ }^{1}$ Universidade Feevale, Programa de Pós-graduação em Qualidade Ambiental, Novo Hamburgo/RS - Brasil

${ }^{2}$ Universidade Feevale, Programa de Aperfeiçoamento Científico, Novo Hamburgo/RS - Brasil

${ }^{3}$ Universidade Feevale, Programa de Iniciação Científica Júnior, Novo Hamburgo/RS - Brasil

*Corresponding Author: Karin Luise dos Santos, Universidade Feevale, Programa de Pós-graduação em Qualidade Ambiental, ERS 239, 2755, Vila Nova, CEP: 93525-075, Novo Hamburgo/RS - Brasil,

e-mail: karinluise@feevale.br

Cite as: Santos, K. L., Panizzon, J., Cenci, M. M., Grabowski, G., \& Jahno, V. D. (2020). Food losses and waste: reflections on the current brazilian scenario. Brazilian Journal of Food Technology, 23, e2019134.

https://doi.org/10.1590/1981-6723.13419

\begin{abstract}
Resumo
Mundialmente, ocorre um incremento populacional de mais de oitenta milhões de pessoas a cada ano, e o Brasil é um dos países mais populosos do mundo. Para garantir a sobrevivência humana na Terra, é preciso rever algumas atitudes relacionadas à utilização dos recursos naturais, os quais afetam diretamente a disponibilidade de alimentos, entre outras necessidades básicas. Nesse contexto, este estudo objetiva avaliar a relação entre o direito do ser humano à alimentação com as perdas e o desperdício de alimentos. Serão avaliados aspectos legais e bioéticos, além de fatores ambientais, econômicos e sociais. Também serão verificadas algumas iniciativas que estão acontecendo em direção à melhoria desses impasses - a perda e o desperdício - no Brasil e as propostas relativas a ações individualizadas. O Brasil é um dos países que mais desperdiçam alimentos no mundo e este cenário é cada vez mais agravado por diversos fatores, incluindo entraves legais que dificultam a doação de alimentos vencidos ou considerados fora do padrão para o consumo, prática que, consequentemente, reduziria a geração de resíduos orgânicos.
\end{abstract}

Palavras-chave: Doação de alimentos; Resíduos orgânicos; Segurança alimentar.

\section{Abstract}

Globally, the world's population increases more than eighty million people each year, and Brazil is one of the world's most populous countries. To ensure the survival of humankind on Earth we need to review attitudes related to the use of natural resources, which directly affect the availability of food and other basic needs. In this context, this study aims to evaluate the relationship between human's rights to food with food waste and loss. Bioethical and legal aspects will be evaluated, as well as environmental, economic and social factors. In addition, we will verify initiatives that are happening towards the improvement of this subject in Brazil, and the proposals related to 
individualized actions. Brazil is one of the countries that most wastes food in the world and there are several factors that contribute to this scenario, such as legal barriers that could facilitate the donation of expired food or those considered out of consumption standards, thereby reducing the generation of organic residues.

Keywords: Food donation; Organic waste; Food security.

\section{Introdução}

O aumento expressivo do número de seres humanos na Terra e suas respectivas ações antrópicas vêm sendo discutidos amplamente na atualidade. De acordo com os dados publicados pela Organização das Nações Unidas (United Nations, 2017), a população mundial, na metade de 2017, era de 7,6 bilhões de pessoas. Contudo, a cada ano, há um aumento de aproximadamente 83 milhões de pessoas na população mundial. Mesmo que os índices de natalidade estejam em decréscimo, estima-se que, em 2030, a população global esteja entre 8,4 e 8,6 bilhões de habitantes, e, em 2050, entre 9,4 e 10,2 bilhões. Neste contexto, o Brasil é o quinto país mais populoso do mundo, correspondendo a 209 milhões de pessoas, em 2017.

Todo este adensamento global requer água e alimento para a sobrevivência da raça humana, que ainda demanda energia, insumos e saneamento básico para poder manter seus hábitos contemporâneos. O relatório da Global Footprint Network (2012) apontou que a humanidade necessita de 1,5 planeta para poder manter este padrão de vida, ou melhor, de consumo, e, com isso, a biocapacidade planetária encontra-se em grande risco.

Dentre os mais graves efeitos desta exploração da natureza, podemos destacar a diminuição de fontes de recursos não renováveis, a perda da biodiversidade e as mudanças climáticas. Além disso, o desperdício de alimentos e os elevados montantes de resíduos gerados a partir destas perdas são temas atuais de grande preocupação e mobilização mundial.

Dados da Food and Agriculture Organization of the United Nations (2013) apontam que 1,3 bilhão de toneladas de alimentos é jogado fora por ano no mundo, ou seja, um terço dos alimentos produzidos é desperdiçado. Esta é uma quantidade muito elevada, que impacta na segurança alimentar e nutricional da população, e mantém diversas vidas em risco.

Além da perda econômica, a FAO avalia que os prejuízos econômicos gerados pelo desperdício de alimentos sejam da ordem de US\$ 700 bilhões do ponto de vista ambiental e US\$ 900 bilhões na dimensão social. Ou seja, ao considerar o tripé da sustentabilidade (econômico, ambiental e social), o custo total relacionado ao desperdício de alimentos situa-se em torno de US\$2,6 trilhões por ano, valor que corresponde ao PIB do Reino Unido, que atualmente representa a quinta maior economia do mundo (Food and Agriculture Organization of the United Nations, 2013). Galian et al. (2016) destacam ainda que o desperdício de alimentos é uma questão ética com a qual toda sociedade civil deveria se preocupar.

Portanto, constitui elevada importância contextualizar este problema em meio ao cenário brasileiro, avaliando quais abordagens estão sendo trabalhadas e sob quais perspectivas estão sendo buscadas as soluções para minimização das perdas e do desperdício de alimentos no país, a fim de verificar se o Brasil está cumprindo a sua parte para assegurar a vida na Terra e garantir condições mínimas para a existência das futuras gerações. Assim, este trabalho tem como objetivo avaliar a relação entre o direito do ser humano à alimentação e as perdas e o desperdício de alimentos. Neste meio, serão avaliados aspectos legais e bioéticos, além de fatores ambientais, econômicos e sociais. Também serão verificadas algumas iniciativas que estão acontecendo em direção a melhoria destes impasses - a perda e o desperdício - no Brasil e as propostas relativas a ações individualizadas. 


\subsection{0 direito humano à alimentação adequada, à segurança alimentar e nutricional, e a bioética}

O direito humano à alimentação adequada (DHAA) foi assegurado inicialmente através da Declaração Universal dos Direitos Humanos, estabelecida em 1948, período pós-guerra. Nela, foi consagrado o direito humano à alimentação no âmbito da garantia de um padrão de vida apropriado. Como a Declaração Universal não possui natureza jurídica de um tratado, foram relacionados a ela, dois pactos que vinculam os Estados: um destes pactos condiz com os direitos civis e políticos, e outro corresponde aos direitos sociais, econômicos e culturais. O direito humano à alimentação está consagrado no Pacto Internacional sobre Direitos Econômicos, Sociais e Culturais (PIDESC) através do direito fundamental de estar ao abrigo da fome e do direito a uma alimentação adequada (Food and Agriculture Organization of the United Nations, 2014).

No Brasil, a Emenda Constitucional n. ${ }^{\circ} 64$ inseriu a alimentação entre os direitos sociais, definidos no artigo 6. ${ }^{\circ}$ da Constituição Federal de 1988. Atualmente, está em sua Emenda de número 90 e define o seguinte:

Art. $6^{\circ}$ - São direitos sociais a educação, a saúde, a alimentação, o trabalho, a moradia, o transporte, o lazer, a segurança, a previdência social, a proteção à maternidade e à infância, a assistência aos desamparados, na forma desta Constituição (Brasil, 1988).

Rangel (2016) corrobora neste sentido ao afirmar que, sendo a alimentação um direito social e objetivado na carta política do Brasil, faz parte dos direitos fundamentais intransferíveis, incessíveis e plenamente exigíveis. Portanto, o direito à alimentação é inerente a qualquer ser humano, sendo intrínseco ao princípio maior da dignidade da pessoa humana.

Portanto, o direito de estar ao abrigo da fome é considerado uma norma absoluta, pois está diretamente ligado ao direito à vida e, assim, deve ser assegurado a todas as pessoas, independentemente do nível de desenvolvimento em que se encontra a nação. Já o direito a uma alimentação adequada é muito mais amplo, pois condiz com a necessidade de favorecer um ambiente econômico, político e social que seja capaz de permitir que as pessoas possam atingir a segurança alimentar pelos seus próprios meios (Food and Agriculture Organization of the United Nations, 2014). O conceito de Segurança Alimentar e Nutricional (SAN), no Brasil, está definido no Artigo 3. ${ }^{\circ}$, da Lei 11.346/2006, que criou o Sistema Nacional de Segurança Alimentar e Nutricional. De um modo geral, ele deve garantir o direito das pessoas ao acesso constante e efetivo a alimentos de qualidade, cuja quantidade seja suficiente, de modo que não comprometa o acesso a outras necessidades essenciais (Brasil, 2006).

A fim de promover práticas capazes de assegurar a Segurança Alimentar e Nutricional à população brasileira, esta mesma legislação (Lei 11.346/2006) instituiu a Política Nacional de Segurança Alimentar e Nutricional (PNSAN), que estabelece os princípios a partir dos quais devem ser desenvolvidas ações de SAN para que seja garantido o direito à alimentação adequada a toda população do país. Para isto, esta política estabelece algumas diretrizes, dentre as quais é possível destacar o incentivo ao abastecimento e a organização de sistemas agroecológicos, sustentáveis e descentralizados, que abrangem desde a extração, a produção, o processamento até a distribuição de alimentos. Além disso, estas ações devem ainda ser ambiental, cultural, econômica e socialmente sustentáveis, além de ter como base as práticas alimentares promotoras de saúde e que respeitem a diversidade cultural (Brasil, 2010).

Nesta direção, a PNSAN sugere que sejam escolhidos sistemas locais, por serem mais adequados e, por este motivo, normalmente são praticados por agricultores familiares, povos e comunidades tradicionais. Estes circuitos permitem a minimização das perdas de qualidade nutricional, evitam o desperdício de energia e de alimentos (que acontece nos deslocamentos ao longo da rede de distribuição), além de incentivar o consumo de produtos locais e assim perpetuar e respeitar às formas de produção ao longo das gerações, favorecendo também o desenvolvimento regional (Brasil, 2013). 
Porém, segundo Ramos Júnior \& Silveira (2011), a globalização, conduzida por um sistema de produção linear e capitalista, fragmenta as comunidades, gerando vulnerabilidade e insegurança sem valores comuns. Com isto, a participação, a solidariedade, a ação coletiva e a responsabilidade, que são enfatizadas pelo regime de direitos humanos, acabam sendo, muitas vezes, negligenciadas pela sociedade.

Neste âmbito, a Declaração Universal sobre Bioética e Direitos Humanos estabeleceu, em 2003, como responsabilidade social e de saúde, que o progresso da ciência e da tecnologia deve fomentar, conforme item "b" do artigo 14. ${ }^{\circ}$, a alimentação e a água adequadas para atender aos direitos fundamentais de qualquer ser humano, independentemente de sua raça, opção religiosa, escolhas políticas e condições socioeconômicas (United Nations Educational, Scientific and Cultural Organization, 2006).

Erhardt \& Perini (2016) ressaltam que abordar as questões relacionadas à qualidade de vida humana, como a alimentação adequada, sob o olhar da bioética. Carvalho \& Rocha (2013) afirmam que a bioética contribui para a construção das sociedades ao estar comprometida com a dimensão social e os autores ainda consideram de extrema importância que o âmbito da bioética seja inserido nas tomadas de decisão sobre as políticas públicas, com o intuito de melhorá-las ao considerar como prioridade os excluídos e mais necessitados, a fim de diminuir as disparidades nas sociedades do continente e em todo o Planeta.

Fortes (2015) corrobora com os autores anteriores ao considerar que a bioética deve ser orientada pelos fundamentos da solidariedade, da justiça, da equidade e da responsabilidade, substanciando a imprescindibilidade de proteção dos mais desfavorecidos, frágeis ou que vivem em situação de vulnerabilidade. $\mathrm{O}$ autor complementa ainda que a bioética deve auxiliar na busca por soluções para conflitos entre os interesses da coletividade e a responsabilidade de proteção à saúde da mesma.

Desta forma, a discussão sobre os aspectos relacionados às perdas e aos desperdícios de alimentos deve ser expandida e inerente a todos os setores da sociedade, pois, em meio às transformações pelas quais o Brasil vem passando, é incontestável a necessidade de pensar sobre a (não) relação entre as pessoas que vivem em situação de fome e a quantidade de comida desperdiçada todos os dias.

\subsection{Perdas e desperdício de alimentos: aspectos econômicos, sociais e ambientais}

Atualmente, o Brasil ocupa o ranking dos 10 países que mais perdem alimentos no mundo, com cerca de $35 \%$ da produção sendo desperdiçada todos os anos (Food and Agriculture Organization of the United Nations, 2015). Diversos cenários contextualizam esta situação e a plataforma online do Governo do Estado do Rio Grande do Sul, por exemplo, destaca que, na Central de Abastecimento do Rio Grande do Sul (CEASA-RS), são geradas 38 toneladas de resíduos orgânicos por dia, o que equivale a uma produção diária de uma cidade de 50 mil habitantes (Food and Agriculture Organization of the United Nations, 2013).

Para uma contextualização global, é preciso entender as diferenças inerentes às perdas e aos desperdícios de alimentos (PDA). As perdas, de um modo geral, ocorrem principalmente durante a produção, a póscolheita e o processamento, em situações nas quais o alimento não é colhido ou acaba sendo danificado em alguma destas etapas, como o armazenamento e o transporte, por exemplo. Estes fatores contribuem para a redução dos alimentos disponíveis para o consumo humano e caracterizam-se como consequências das ineficiências na cadeia produtiva, tais como infraestrutura e logística deficientes e/ou falta de tecnologias para a produção. Já o desperdício é definido como o descarte intencional de produtos alimentícios apropriados para o consumo humano, sendo decorrente, portanto, do próprio comportamento dos indivíduos (Food and Agriculture Organization of the United Nations, 2013).

Freire Junior \& Soares (2017) ratificam esta definição ao afirmar que o desperdício ocorre quando alimentos que não estão estragados, ou seja, ainda estariam aptos para o consumo, são jogados fora por estarem com uma aparência desagradável, por serem considerados feios, deformados ou fora do padrão. Os autores destacam que muitas perdas são geradas dentro das casas. Os principais fatores relacionados a estas perdas dentro das unidades familiares são: comprar muitos alimentos sem planejar as refeições em que 
serão utilizados, armazená-los de forma indevida, preparar uma quantidade de comida maior do que será consumida e colocar no prato porções além do que será possível comer durante as refeições.

Uma reflexão feita por Rodrigues (2018) mostrou que uma família brasileira com cinco pessoas gasta, em média, $\mathrm{R} \$ 1.532,50$ mensalmente com alimentação e, ao considerar a média mundial de 30\% de desperdício, evidenciou que, deste valor, $\mathrm{R} \$ 459,75$ são gastos com alimentos que viraram lixo. Ou seja, quase $\mathrm{R} \$ 500,00$ da renda familiar foram perdidos.

Além dos fatores sociais e econômicos, existem diversos impactos ambientais causados pelo desperdício de alimentos, dentre os quais podemos destacar a grande quantidade de resíduos gerados. De acordo com o Plano Estadual de Resíduos Sólidos do Rio Grande do Sul (Rio Grande do Sul, 2014), só no ano de 2014, foram gerados no estado mais de três milhões de toneladas de resíduos sólidos urbanos (RSU). Destes, aproximadamente 1,9 tonelada é correspondente à fração orgânica dos resíduos sólidos urbanos (FORSU), ou seja, matéria orgânica proveniente, dentre outras fontes, também do desperdício de alimentos. Mas este não é apenas um cenário do Rio Grande do Sul. O Plano Nacional de Resíduos Sólidos (Brasil, 2012) destaca que $51,40 \%$ do total de resíduos sólidos urbanos gerados no país são correspondentes à matéria orgânica.

De acordo com a 17. Avaliação de Perdas no Varejo Brasileiro de Supermercados (Associação Brasileira de Supermercados, 2017), apontou-se que só os supermercados brasileiros perderam, em faturamento, $\mathrm{R} \$$ 7,11 bilhões em alimentos descartados, em 2016. Contudo, estima-se que, em toda a cadeia produtiva (campo, indústria, varejo e consumidor), o valor relativo às perdas seja ainda maior.

O tema de desperdícios de alimentos possui tamanha relevância e abrangência mundial que acabou levando diversos países a assumirem compromissos em marcos estratégicos internacionais, como o Acordo de Paris, firmado na 21. ${ }^{a}$ Conferência das Partes da Convenção-Quadro das Nações Unidas sobre Mudança do Clima, a Agenda 2030 e o Plano da Comunidade de Estados Latino-Americanos e Caribenhos para a Segurança Alimentar, Nutrição e Erradicação da Fome 2025 (Câmara Interministerial de Segurança Alimentar e Nutricional, 2017).

De todas estas estratégias, destaca-se a Agenda 2030, na qual, em 2015, chefes de Estado, de Governo, e altos membros da Organização das Nações Unidas definiram os Objetivos do Desenvolvimento Sustentável (ODS), no qual é proposta uma atuação em nível mundial, promovida pelos governos, empresas, instituições de ensino e a sociedade civil, para atingir os 17 objetivos e suas respectivas 169 metas, que possibilitem a erradicação da pobreza e proporcionem uma vida digna para todos, neste Planeta (Brasil, 2017).

Reduzir o desperdício de alimentos é a forma mais sustentável de diminuir perdas de recursos naturais. E reduzir o desperdício de alimentos pela metade per capita mundial, em nível de varejo e do consumidor, é uma das metas relacionadas aos Objetivos do Desenvolvimento Sustentável aprovados pelas Nações Unidas. Esta meta consiste em diminuir as perdas de alimentos em toda a rede alimentar, desde a produção à distribuição, abrangendo ainda as perdas pós-colheita, até 2030.

Ainda sobre os Objetivos do Desenvolvimento Sustentável, um dos maiores desafios está em erradicar a pobreza e a fome (ODS1 e ODS2, respectivamente), enquanto mantém-se a segurança alimentar sustentável para todos em um mundo denso e dramaticamente desigual. Embora o mundo tenha conseguido reduzir a pobreza de acordo com as metas dos Objetivos de Desenvolvimento do Milênio (ODMs), a segurança alimentar e a nutrição adequada não foram alcançadas (Brasil, 2017).

Segundo Rosaneli et al. (2015), a pobreza pode ser contextualizada como um fenômeno complexo e multidimensional, que priva grande parte da população mundial do acesso à alimentação, o que acaba gerando reflexos, como o baixo desenvolvimento físico, psicológico e social. Além disso, outros fatores relacionados às desigualdades, como a educação, a participação política e os cuidados com a saúde, acabam mantendo estas pessoas reféns da condição de miséria extrema.

O número de pessoas subnutridas aumentou para 815 milhões em 2016, acima dos 777 milhões em 2015. Além disso, grande parte do recente aumento da insegurança alimentar pode ser atribuída ao maior número 
de conflitos e, muitas vezes, é exacerbada por choques relacionados ao clima. Mesmo em alguns ambientes pacíficos, a segurança alimentar deteriorou-se com desacelerações econômicas, que tendem a dificultar o acesso a alimentos para os pobres, como é o caso do Brasil (Food and Agriculture Organization of the United Nations, 2017).

Este fato é evidenciado no país a partir de dados da Pesquisa Nacional por Amostra de Domicílios (PNAD), que mostram que, embora o índice de extrema pobreza tenha reduzido de 8,1\% em 2004 para 2,7\% em 2015 e o de pobreza, de $23,5 \%$ para $6,6 \%$ no mesmo período, a taxa de desocupação da força de trabalho passou de 4,9\% no primeiro trimestre de 2012 para $8,5 \%$, no mesmo período de 2017 .

Outro ponto que merece destaque é o número de mulheres que sofrem de anemia em todo o mundo: quase um terço (ou 33\%) das mulheres em idade reprodutiva, fator que também coloca a nutrição e a saúde de muitas crianças em risco. Adicionalmente a esta situação, múltiplas formas de desnutrição estão coexistindo, com países que experimentam simultaneamente altas taxas de desnutrição infantil e obesidade adulta (Food and Agriculture Organization of the United Nations, 2017).

Ou seja, apesar de a fome não ser mais considerada um problema estrutural, sabe-se que a insegurança alimentar e nutricional pode ser agravada em situações de crise econômica, como a que o Brasil vivencia atualmente (Câmara Interministerial de Segurança Alimentar e Nutricional, 2017).

\section{Abordagens para minimização das perdas e dos desperdícios de alimentos}

Peixoto \& Pinto (2016) destacam que o aumento dos cuidados por indústrias de alimentos, varejistas e consumidores pode reduzir o desperdício de alimentos em países industrializados. Neste âmbito, instrumentos legais que reduzam as brechas mercadológicas que levem em consideração o planejamento entre criação de produtos e utilização, ou produzam a cultura de consumo consciente, teriam influência direta e resultados seriam potencializados. Os autores enfatizam também que, apesar de as medidas de mitigação de desperdício terem custos significativos, estas oferecem globalmente uma eficiência e equidade maiores.

Contudo, um documento publicado pelo Programa das Nações Unidas para o Meio Ambiente (United Nations Environmental Programme, 2014) destaca que, antes de estabelecer qualquer estratégia ou política para prevenir ou reduzir o desperdício de alimentos, é importante entender como eles são gerados em escala nacional ou regional. A partir de então, devem ser priorizadas áreas de ação e mensuradas as mudanças conquistadas a partir delas. Isso incluiria tanto as perdas e os desperdícios que surgem na cadeia de suprimento de alimentos e bebidas como aqueles gerados pelos consumidores dentro e fora de suas casas.

A disponibilidade de informações sobre a quantidade, o motivo pelo qual são geradas as perdas associadas e o destino destes alimentos considerados não comestíveis e que são removidos da cadeia de fornecimento de alimentos é escassa em muitos países, cidades, empresas e outras entidades. Isso implica no desenvolvimento de medidas que evitem as PDAs, bem como a identificação do surgimento de métodos mais eficazes. Em resumo, gerenciar algo não mensurado se torna uma adversidade. Além disso, quando não há consistência nas definições ou um arranjo contábil coerente com relatórios, a comparação de dados internamente ou acerca das instituições ao longo do tempo e para que seja possível a formulação de conclusões, é dificultada (World Resources Institute, 2017).

Algumas outras medidas também são requeridas para que sejam estabelecidas redes e que estas possam se comunicar de forma eficiente. Estas conexões devem envolver produtores de alimentos, estabelecimentos agroindustriais, distribuidores e comerciários (atacado e varejo, os quais integram a cadeia produtiva), administrações, órgãos e demais autoridades públicas, e também quem consome. Esta relação deve haver para que sejam reduzidas as disparidades relacionadas com o volume de oferta e demanda, em diversas condições, tais como: a) quando apodrece parte do que foi produzido no campo, devido ao produtor não encontrar compradores ou preços que cubram os custos da produção; b) quando uma pessoa prepara uma refeição para cinco familiares, mas apenas três comparecem; c) quando um estabelecimento reduz a 
quantidade do pedido sem antecedência e os fornecedores ficam sem compradores alternativos para fechar negócio, ou d) quando um restaurante planeja de forma indevida a demanda e estoca produtos além do necessário, tendo que descartá-los posteriormente (Food and Agriculture Organization of the United Nations, 2013).

De encontro a estas situações, estão tramitando, na Câmara e no Senado Federal, diversos Projetos de Lei que, de um modo geral, autorizam ou obrigam empresas comerciárias do ramo alimentício a fazerem doações para entidades beneficentes, ou sem fins lucrativos, a bancos de alimentos, direta ou indiretamente a pessoas em condições vulneráveis. Tanto concessores quanto instituições recebedoras devem garantir seguridade sadia dos alimentos conforme legislação vigorante, amparada na isenção dos primeiros de prejuízos à saúde dos consumidores finais, na falta de dolo ou negligência. Em alternativa àqueles alimentos impróprios para o consumo humano, alguns projetos promovem a doação de alimentos para alimentação animal ou compostagem. No entanto, não suprimem os riscos legais aos quais atualmente estão submetidos os doadores pelos Códigos Civil e de Defesa do Consumidor, relacionados aos problemas que possam ocorrer no que tangem aos danos à saúde das pessoas que recebem as doações, mesmo que não tenham sido malintencionados (Peixoto \& Pinto, 2016).

Um estudo publicado em 2018 pela BASF, uma empresa química alemã, identificou que, no Brasil, aspectos, como estas falhas nas regulações, além de alguns hábitos culturais e a falta de consciência geral a respeito dos efeitos perversos das perdas e dos desperdícios de alimentos, contribuem para a situação atual. Também aponta que o preparo de refeições a partir de frutas e vegetais sem boa aparência, a compra de produtos de fim de feira com preços inferiores e o consumo de partes menos nobres dos alimentos são hábitos não usuais da população brasileira, o que acaba por agravar ainda mais o quadro no país.

Com o objetivo de coordenar ações direcionadas a prevenir e reduzir as perdas e o desperdício de alimentos no Brasil, através da gestão integrativa entre setores nas investidas governamentais e sociais, alinhada com a Política Nacional de Segurança Alimentar e Nutricional, foi lançada ao final de 2017 a Estratégia Intersetorial Para a Redução de Perdas e Desperdícios de Alimentos no Brasil. Esta estratégia consiste em uma ferramenta que será utilizada para possibilitar uma busca abrangente a fim de identificar pontos críticos, causas e possíveis soluções para as perdas e os desperdícios em diversos níveis, assim como graus de intervenção, determinando um plano de ação que englobe diferentes atores (Câmara Interministerial de Segurança Alimentar e Nutricional, 2017).

Dentre estas ações, destacam-se: o fomento à realização de pesquisas que auxiliem na determinação das causas e possíveis soluções das perdas e dos desperdícios de alimentos no Brasil; o fomento à inovação tecnológica e às tecnologias sociais direcionadas à redução das PDAs; o apoio a campanhas educativas, ações de comunicação e divulgação de boas práticas junto à população, visando prevenir o desperdício de alimentos e a proposição de alterações nos marcos legais existentes no Brasil, além do suporte à sanção de dispositivos legais em tramitação, de modo a aprimorar o seguimento da doação de alimentos (Câmara Interministerial de Segurança Alimentar e Nutricional, 2017).

Portanto, é visível que o país tem caminhado em busca de uma melhoria neste assunto. Contudo, a situação política não favorável, refletida em uma grande crise econômica, tende a estagnar todas as movimentações que estejam sendo feitas no âmbito governamental. Em relação aos Projetos de Lei, foi realizada uma busca utilizando a palavra-chave "doação de alimentos", no Portal da Câmara dos Deputados do Brasil, no qual é possível consultar todas as Proposições do Legislativo disponíveis para acesso público (Brasil, 2018). O portal permite aplicar filtros para refinar a busca e apresentar resultados específicos. Foram gerados 422 resultados gerais, dos quais 290 estão em tramitação e, ao final, foram obtidas 27 proposições que se referem ou têm relação com a doação de alimentos. Foram considerados os projetos em que o termo buscado não aparece na Ementa ou na Explicação da Ementa, mas consta no teor do texto, conforme o Quadro 1.

De acordo com o Portal da Câmara dos Deputados, um projeto que está "Tramitando em Conjunto" significa estar apensado a outro projeto com conteúdo similar. Todos os assemelhados tramitam como um 
único projeto e, caso seja aprovado, é criado um Substitutivo. Já um projeto que esteja em situação de "Pronto para Pauta" encontra-se na última etapa que precede a votação pela Câmara. Nesse contexto, existem 20 tramitando em conjunto; três aguardam a designação de um relator, o qual irá emitir um parecer, podendo ser favorável ou não, bem como sugerir alterações ou modificar o texto. Apenas um projeto aguarda a emissão do parecer e dois estão prontos para serem apresentados em pauta e votados.

Cabe ressaltar que São Paulo é o estado brasileiro com o maior número de proposições dessa natureza, diante do assunto, e aparece com cinco propostas. O restante dos projetos está aleatoriamente distribuído entre outros estados. Isso pode estar relacionado a vários fatores, entre eles a geração de resíduos orgânicos e a quantidade de alimentos desperdiçados todos os anos no território paulista, assim como pode refletir o grande número de iniciativas nesse sentido.

De qualquer forma, alguns projetos de lei estão no legislativo a mais de 20 anos sem receber definição, conforme mostra o Quadro 1. Este assunto deveria ser tratado de forma prioritária, visto a imensa quantidade de pessoas em situação de fome no país e ainda todos os impactos ambientais, sociais e econômicos causados pelas perdas e pelo desperdício de alimentos. Cabe aqui um questionamento sobre a [pouca] importância concedida pelos governantes para este tema, evidenciada pela falta de urgência que rege implementação de normativas capazes de evitar que toneladas de alimentos sejam descartados todos os dias no país.

Quadro 1. Projetos de Lei relacionados à doação de alimentos em situação de tramitação, disponíveis para consulta no Portal da Câmara dos Deputados do Brasil.

\begin{tabular}{|c|c|c|c|}
\hline $\begin{array}{l}\text { Projeto de } \\
\text { Lei (PL) }\end{array}$ & Tema do projeto & $\begin{array}{c}\text { Data de } \\
\text { Apresentação }\end{array}$ & Situação \\
\hline $\begin{array}{c}\text { PL } \\
10288 / 2018\end{array}$ & Doação de alimentos próximos à data de validade. & $23 / 05 / 2018$ & $\begin{array}{c}\text { Tramitando } \\
\text { em Conjunto }\end{array}$ \\
\hline $\begin{array}{c}\text { PL } \\
10260 / 2018\end{array}$ & Dispõe sobre o desperdício alimentar. & $16 / 05 / 2018$ & $\begin{array}{l}\text { Tramitando } \\
\text { em Conjunto }\end{array}$ \\
\hline PL 9202/2017 & $\begin{array}{c}\text { Dispõe sobre a doação de alimentos, dentro dos prazos de } \\
\text { validade, para consumo humano, e, com prazos de validade } \\
\text { vencidos, para a fabricação de ração animal ou compostagem. }\end{array}$ & 28/11/2017 & $\begin{array}{l}\text { Tramitando } \\
\text { em Conjunto }\end{array}$ \\
\hline PL 8874/2017 & $\begin{array}{l}\text { Dispõe sobre a doação de alimentos por supermercados, } \\
\text { restaurantes e estabelecimentos assemelhados. }\end{array}$ & $18 / 10 / 2017$ & $\begin{array}{l}\text { Tramitando } \\
\text { em Conjunto }\end{array}$ \\
\hline PL 7928/2017 & $\begin{array}{c}\text { Dispõe sobre a caracterização de Entidade de Assistência Social e } \\
\text { os serviços prestados, dentre eles a doação de alimentos. }\end{array}$ & $27 / 06 / 2017$ & $\begin{array}{l}\text { Aguardando } \\
\text { Parecer }\end{array}$ \\
\hline PL 7507/2017 & $\begin{array}{l}\text { Dispõe sobre a doação de alimentos por supermercados, } \\
\text { restaurantes, feiras, sacolões e estabelecimentos assemelhados. }\end{array}$ & $26 / 04 / 2017$ & $\begin{array}{l}\text { Tramitando } \\
\text { em Conjunto }\end{array}$ \\
\hline PL 6898/2017 & $\begin{array}{l}\text { Institui a Política Nacional de Combate ao Desperdício e à Perda } \\
\text { de Alimentos (PNCDA) e altera a Lei n. }{ }^{\circ} 9.249 \text {, de } 26 \text { de } \\
\text { dezembro de } 1995{\text { a Lei } .^{\circ}}^{\circ} 9.605 \text {, de } 12 \text { de fevereiro de } 1998 \text {, e } \\
\text { a Lei n. } .^{\circ} 12.305 \text {, de } 2 \text { de agosto de } 2010 .\end{array}$ & $14 / 02 / 2017$ & $\begin{array}{l}\text { Tramitando } \\
\text { em Conjunto }\end{array}$ \\
\hline PL 5691/2016 & Dispõe sobre a doação de alimentos e de remédios. & 28/06/2016 & $\begin{array}{l}\text { Tramitando } \\
\text { em Conjunto }\end{array}$ \\
\hline PL 5620/2016 & $\begin{array}{l}\text { Dispõe sobre regras de conduta a serem obedecidas pelos } \\
\text { estabelecimentos de comércio alimentar, e dá outras } \\
\text { providências. }\end{array}$ & 20/06/2016 & $\begin{array}{l}\text { Tramitando } \\
\text { em Conjunto }\end{array}$ \\
\hline PL 4746/2016 & $\begin{array}{l}\text { Concede incentivo fiscal do imposto de renda de pessoa jurídica } \\
\text { comerciante varejista de produtos alimentícios, com a doação de } \\
\text { alimentos, pelo preço de custo, a instituições públicas. }\end{array}$ & $15 / 03 / 2016$ & $\begin{array}{l}\text { Aguardando } \\
\text { Designação de } \\
\text { Relator } \\
\end{array}$ \\
\hline PL 4742/2016 & $\begin{array}{c}\text { Dispõe sobe a regulamentação da doação de alimentos por } \\
\text { instituições públicas ou sociedades de economia mista, entidades } \\
\text { filantrópicas ou beneficentes. }\end{array}$ & $15 / 03 / 2016$ & $\begin{array}{l}\text { Aguardando } \\
\text { Designação de } \\
\text { Relator } \\
\end{array}$ \\
\hline PL 3769/2015 & $\begin{array}{c}\text { Dispõe sobre a criação do Programa Sobras e Aparas e dá outras } \\
\text { providências. }\end{array}$ & $26 / 11 / 2015$ & $\begin{array}{l}\text { Tramitando } \\
\text { em Conjunto }\end{array}$ \\
\hline $\begin{array}{c}\text { PL } \\
3620 / 2015 \\
\end{array}$ & \multicolumn{3}{|c|}{ Dispõe sobre eximir de sanções civis e penais doadores de alimentos em condições de consumo. } \\
\hline $\begin{array}{c}\text { PL } \\
\text { 3070/2015 }\end{array}$ & \multicolumn{3}{|c|}{ Estabelece regras específicas para erradicar o desperdício de alimentos. } \\
\hline
\end{tabular}


Quadro 1. Continuação...

\begin{tabular}{|c|c|c|c|}
\hline $\begin{array}{l}\text { Projeto de } \\
\text { Lei (PL) }\end{array}$ & Tema do projeto & $\begin{array}{c}\text { Data de } \\
\text { Apresentação }\end{array}$ & Situação \\
\hline $\begin{array}{c}\text { PL } \\
2775 / 2015 \\
\end{array}$ & \multicolumn{3}{|c|}{ Dispõe sobre a doação de alimentos por supermercados e estabelecimentos similares. } \\
\hline $\begin{array}{c}\text { PL } \\
2574 / 2015 \\
\end{array}$ & \multicolumn{3}{|c|}{$\begin{array}{l}\text { Determina a doação de alimentos dentro do prazo de validade e de perecíveis apreendidos a entidades } \\
\text { sem fins lucrativos. }\end{array}$} \\
\hline $\begin{array}{c}\text { PL } \\
2352 / 2015 \\
\end{array}$ & \multicolumn{3}{|c|}{$\begin{array}{l}\text { Dispõe sobre a obrigação de estabelecimentos que produzam ou comercializem alimentos disponibilizem } \\
\text { os considerados fora dos padrões de comercialização para a alimentação. }\end{array}$} \\
\hline $\begin{array}{c}\text { PL } \\
2194 / 2015\end{array}$ & \multicolumn{3}{|c|}{$\begin{array}{l}\text { Dispõe sobre a obrigação dos estabelecimentos de firmar acordos com entidades assistenciais com o fim } \\
\text { de entregar produtos adequados à alimentação humana, os quais estejam fora dos padrões de } \\
\text { comercialização. }\end{array}$} \\
\hline $\begin{array}{c}\text { PL } \\
1788 / 2015 \\
\end{array}$ & \multicolumn{3}{|c|}{$\begin{array}{l}\text { Sobre a obrigatoriedade de os estabelecimentos darem a correta destinação aos alimentos que não forem } \\
\text { vendidos e permitir a doação do que não for comercializado. }\end{array}$} \\
\hline $\begin{array}{c}\text { PL } \\
1748 / 2015 \\
\end{array}$ & \multicolumn{3}{|c|}{ Institui o Programa Nacional de doação de alimentos. } \\
\hline $\begin{array}{c}\text { PL } \\
6006 / 2013 \\
\end{array}$ & \multicolumn{3}{|c|}{ Dispõe sobre a doação de alimentos às instituições de caridade. } \\
\hline $\begin{array}{c}\text { PL } \\
5958 / 2013 \\
\end{array}$ & \multicolumn{3}{|c|}{$\begin{array}{l}\text { Institui normas básicas sobre alimentos visando permitir a reutilização de alimentos preparados, para } \\
\text { fins de doação. }\end{array}$} \\
\hline $\begin{array}{c}\text { PL } \\
2550 / 2011 \\
\end{array}$ & \multicolumn{3}{|c|}{$\begin{array}{c}\text { Dispõe sobre a instituição do Programa Nacional de Coleta e Doação de Alimentos e dá outras } \\
\text { providências. }\end{array}$} \\
\hline $\begin{array}{c}\text { PL } \\
7060 / 2010\end{array}$ & \multicolumn{3}{|c|}{ Dispõe sobre a responsabilidade civil e criminal de doadores de alimentos. } \\
\hline $\begin{array}{c}\text { PL } \\
2144 / 2007 \\
\end{array}$ & \multicolumn{3}{|c|}{ Cria o Programa de Redistribuição de Alimentos Excedentes e dá outras providências. } \\
\hline $\begin{array}{c}\text { PL } \\
2713 / 2003 \\
\end{array}$ & \multicolumn{3}{|c|}{ Dispõe sobre a responsabilidade civil e criminal das pessoas que doam alimentos. } \\
\hline $\begin{array}{c}\text { PL } \\
4747 / 1998 \\
\end{array}$ & \multicolumn{3}{|c|}{$\begin{array}{l}\text { Dispõe sobre a isenção de responsabilidades da pessoa que doar alimentos direta ou indiretamente, a } \\
\text { pessoas carentes. }\end{array}$} \\
\hline
\end{tabular}

Contudo, enquanto o legislativo não toma nenhuma ação, existem alguns cases brasileiros que cabem ser destacados.

\section{Algumas iniciativas de destaque no Brasil}

Como já apontado, grande parte dos desperdícios ocorre dentro das residências e, portanto, fazem-se necessárias ações que sejam iniciadas dentro das unidades familiares. A Food and Agriculture Organization of the United Nations (2018) indica que conscientização é o primeiro passo para prevenção e deve iniciar por campanhas educativas voltadas para o consumo.

Neste sentido, algumas iniciativas brasileiras estão recebendo destaque, como a Save Food Brasil, uma iniciativa vinculada a FAO que busca estimular a sinergia, a colaboração e a intercomunicação entre grupos e corporações com o fito de promover a redução das perdas e do desperdício de alimentos no Brasil. Seus objetivos principais são: construir uma rede de especialistas brasileiros na área; incentivar e simplificar a comunicação entre setores; manter a rede atualizada, e buscar a sensibilização da sociedade acerca da relevância do assunto (Save Food Brasil, 2018).

A iniciativa \#SemDesperdício foi lançada pela ONG WWF-Brasil, em parceria com a Embrapa e a FAO, a qual trabalha para expandir a "conscientização dos usuários brasileiros a respeito do desperdício de alimentos e impulsionar uma mudança positiva nos costumes alimentares". Esta iniciativa traz a ideia de associar os hábitos alimentares da população com costumes individuais ou coletivos, que geram desperdícios e acabam por representar o alimento que falta ao outro, ou o recurso financeiro que falta para as pessoas, e ainda a escassez de recursos em nível global (Sem Desperdício, 2018).

Outra iniciativa que merece destaque é o Programa Mesa Brasil, desenvolvido pelo SESC. Este programa busca empresas que queiram exercitar a responsabilidade social através da doação de alimentos, cuja 
qualidade é avaliada e que, posteriormente, são transportados até o público beneficiário sob condições adequadas de consumo, combatendo assim o desperdício de alimentos e reduzindo a fome no país (Mesa Brasil, 2018).

A Fruta Imperfeita é uma iniciativa que busca a propagação do consumo consciente, atuando como promotor da conexão entre os fornecedores e os usuários. De modo geral, os alimentos que seriam descartados pelos pequenos produtores são comprados e revendidos em forma de cestas que possuem 14 variedades de frutas, legumes e verduras. Os consumidores podem adquirir os produtos de forma avulsa ou ainda através de um formato de assinatura semanal ou quinzenal. Esta iniciativa já salvou em torno de 300 toneladas de alimentos em apenas dois anos de atividades (Fruta Imperfeita, 2018).

O Banco de Alimentos é uma Organização Não Governamental (ONG), que visa mitigar o desperdício de alimentos ao revender os excedentes de produtos, comprados diretamente de quem produz. Atualmente, existem mais de 40 instituições cadastradas no projeto, com um atendimento estimado em mais de 22 mil pessoas por mês. A ONG atua em todo o país de três principais formas: a primeira consiste em coletar os excedentes de estabelecimentos comerciais e levá-los até instituições de caridade. A segunda frente está relacionada com a educação ambiental, na qual são realizadas palestras, workshops e oficinas aos profissionais das próprias ONGs. A terceira frente está em estender essas ações educativas para a população em geral, buscando a conscientização da própria sociedade (Banco de Alimentos, 2018).

\section{Conclusão}

Ainda que a alimentação esteja ancorada ao direito à vida, a educação permeia como direito social fundamental de interesse coletivo, concretizada pela sociedade como um bem comum que se quer preservar. Não seria interessante se essa perspectiva pudesse ser aplicada também aos alimentos? Partindo do entendimento de que a alimentação é um dos fatores essenciais para a garantia de continuidade, desenvolvimento e manutenção da vida na Terra, dá-se, ao alimento, a mesma importância? Assim como existem milhões de pessoas consideradas analfabetas no Brasil, existem aquelas para as quais o alimento que chega não é suficiente para serem consideradas nutridas.

Ainda que iniciativas promissoras estejam trabalhando para otimizar a distribuição de produtos e garantir o acesso à alimentação mínima, o país carece de decisões públicas efetivas que favoreçam significativamente essa porção da população. A educação, como direito primordial, é uma ferramenta extremamente importante na construção de uma sociedade equalitária, mas que deve vir acompanhada de políticas públicas eficientes voltadas ao bem-estar comum, que atuem majoritariamente na não geração de resíduos e combatam o desperdício de maneira inteligente; que sejam inclusivas; que incentivem as produções locais em pequena escala e na descentralização da distribuição e da obtenção de produtos alimentícios; que respeitem o meio ambiente e apoiem práticas sustentáveis de produção, e que garantam uma alimentação digna e de qualidade para o povo brasileiro.

\section{Agradecimentos}

Ao CNPq, à Coordenação de Aperfeiçoamento de Pessoal de Nível Superior (CAPES) e à Universidade Feevale.

\section{Referências}

Associação Brasileira de Supermercados - ABRAS. (2017). 17ª Avaliação de perdas no varejo brasileiro de supermercados. São Paulo. Recuperado em 14 de junho de 2018, de http://www.abrasnet.com.br/pdf/Apres_perdas_17.pdf

Banco de Alimentos. (2018). Recuperado em 19 de junho de 2018, de https://www.bancodealimentos.org.br/

Brasil. (1988, outubro 5). Constituição da República Federativa do Brasil de 1988. Diário Oficial da União, Brasília. Recuperado em 13 de maio de 2018, de http://www.planalto.gov.br/ccivil_03/constituicao/constituicao.htm 
Brasil. Sistema Nacional de Segurança Alimentar e Nutricional - SISAN. (2006, setembro 18). Cria o Sistema Nacional de Segurança Alimentar e Nutricional - SISAN com vistas em assegurar o direito humano à alimentação adequada e dá outras providências (Lei n 11.346, de 15 de setembro de 2006). Diário Oficial da União, Brasília. Recuperado em 14 de junho de 2018, de http://www.planalto.gov.br/ccivil_03/_ato2004-2006/2006/lei//11346.htm

Brasil. (2010, agosto 26). Regulamenta a Lei $n^{\circ}$ 11.346, de 15 de setembro de 2006, que cria o Sistema Nacional de Segurança Alimentar e Nutricional - SISAN com vistas a assegurar o direito humano à alimentação adequada, institui a Política Nacional de Segurança Alimentar e Nutricional - PNSAN, estabelece os parâmetros para a elaboração do Plano Nacional de Segurança Alimentar e Nutricional, e dá outras providências (Decreto $n^{\circ} 7.272$, de 25 de agosto de 2010). Diário Oficial da União, Brasília. Recuperado em 13 de maio de 2018, de http://www.planalto.gov.br/ccivil_03/_Ato2007-2010/2010/Decreto/D7272.htm

Brasil. Ministério do Meio Ambiente. (2012). Plano nacional de resíduos sólidos (103 p.). Brasília.

Brasil. Ação Brasileira pela Nutrição e Direitos Humanos - ABRANDH. (2013). O direito humano à alimentação adequada e o sistema nacional de segurança alimentar e nutricional. Brasília: Ministério do Desenvolvimento Social e Combate à Fome. Recuperado em 14 de junho de 2018, de http://www.mds.gov.br/webarquivos/publicacao/seguranca_alimentar/DHAA_SAN.pdf

Brasil. (2017). Relatório nacional voluntário sobre os objetivos do desenvolvimento sustentável. Brasília. Recuperado em 12 de junho de 2018, de http://www4.planalto.gov.br/ods/publicacoes/relatoriovoluntario_brasil2017port.pdf

Brasil. Câmara dos Deputados. (2018). Projetos de lei e outras proposições. Brasília. Recuperado em 19 de setembro de 2018 , de http://www.camara.leg.br/buscaProposicoesWeb/pesquisaSimplificada

Câmara Interministerial de Segurança Alimentar e Nutricional - CAISAN. (2017). Estratégia intersetorial para a redução de perdas e desperdício de alimentos no Brasil. Brasília. Recuperado em 14 de junho de 2018, de http://www.mds.gov.br/webarquivos/arquivo/seguranca_alimentar/caisan/Publicacao/Caisan_Nacional/PDA.pdf

Carvalho, L. R. T., \& Rocha, D. G. (2013). Programa de Aquisição de Alimentos: A lente bioética na segurança alimentar. Revista Bioética, (21), 278-290.

Erhardt, C., \& Perini, C. C. (2016). Bioética e o direito humano à alimentação adequada. In C. F. Rosaneli (Ed.), Contextos, conflitos e escolhas em alimentação e bioética. Curitiba: PUCPRess.

Food and Agriculture Organization of the United Nations - FAO. (2013). Food wastage footprint: Impacts on natural resources. Rome. Recuperado em 12 de junho de 2016, de http://www.fao.org/docrep/018/i3347e/i3347e.pdf

Food and Agriculture Organization of the United Nations - FAO. (2014). O direito à alimentação no quadro internacional dos direitos humanos e nas Constituições. Rome. Recuperado em 14 de junho de 2018, de http://www.fao.org/3/a-i3448o.pdf

Food and Agriculture Organization of the United Nations - FAO. (2015). Food wastage footprint \& climate change. Rome. Recuperado em 15 de maio de 2018, de http://www.fao.org/3/a-bb144e.pdf

Food and Agriculture Organization of the United Nations - FAO. (2017). The state of food security and nutrition in the world. Rome. Recuperado em 12 de junho de 2016, de http://www.fao.org/3/a-17695e.pdf

Food and Agriculture Organization of the United Nations - FAO. (2018). Retail food waste action guide. Rome. Recuperado em 18 de junho de 2016, de http://www.refed.com/downloads/Retail_Guide_Web.pdf

Fortes, P. A. C. (2015). Refletindo sobre valores éticos da Saúde Global. Revista Saúde e Sociedade, 24(Supl. 1), 152-161.

Freire Junior, M., \& Soares, A. G. (2017). Redução do desperdício de alimentos. Embrapa. Recuperado em 12 de junho de 2018, de https://ainfo.cnptia.embrapa.br/digital/bitstream/item/164602/1/Foler-CGPE-13931.pdf

Fruta Imperfeita. (2018). Recuperado em 20 de junho de 2018, de https://frutaimperfeita.com.br/

Galian, L. C. F., Santos, S. S., \& Madrona, G. S. (2016). Análise do desperdício de alimentos em uma unidade de alimentação e nutrição. Revista GEINTEC, 6(2), 3121-3127. http://dx.doi.org/10.7198/S2237-0722201600020010

Global Footprint Network - GFN. (2012). The National Footprint Accounts, 2011 edition. Recuperado em 29 de maio de 2018, de https://www.footprintnetwork.org/content/images/uploads/NFA_2011_Edition.pdf

Mesa Brasil. (2018). Recuperado em 20 de junho de 2018, de http://www.sesc.com.br/portal/site/mesabrasilsesc/home/

Peixoto, M., \& Pinto, H. S. (2016). Desperdício de alimentos: Questões socioambientais, econômicas e regulatórias (Boletim Legislativo, Vol. 41). Brasília: Senado Federal. Recuperado em 14 de junho de 2018, de

https://www12.senado.leg.br/publicacoes/estudos-legislativos/tipos-de-estudos/boletins-legislativos/bol41

Ramos Júnior, D. P., \& Silveira, E. D. (2011). Globalização multicultural, direitos universais humanos e socioambientais. Revista de Direito Econômico e Socioambiental, 2(1), 11-39. http://dx.doi.org/10.7213/rev.dir.econ.socioambienta.02.001.A001

Rangel, T. L. V. (2016). Bioética, biossegurança e segurança alimentar e nutricional: Um exame tridimensional do direito humano à alimentação adequada. Recuperado em 19 de junho de 2018, de http://www.conteudojuridico.com.br/artigo,bioeticabiosseguranca-e-seguranca-alimentar-e-nutricional-um-exame-tridimensional-do-direito-humano-a-aliment,56186.html

Rio Grande do Sul. Governo do Estado. (2014). Plano Estadual de Resíduos Sólidos do Rio Grande do Sul - PERS-RS:20152034. Porto Alegre: Secretaria do Meio Ambiente e Infraestrutura. Recuperado em 28 de maio de 2018, de https://www.sema.rs.gov.br/plano-estadual-de-residuos-solidos

Rodrigues, P. (2018). Projeto incentiva consumo consciente de hortaliças para evitar o desperdício nas residências. Hortaliças em Revista: Embrapa Hortaliças, 6(23), 6-15.

Rosaneli, C. F., Ribeiro, A. L. C., Assis, L., Silva, T. M., \& Siqueira, J. E. (2015). A fragilidade humana diante da pobreza e da fome. Revista Bioética, 23(1), 89-97. http://dx.doi.org/10.1590/1983-80422015231049

Save Food Brasil. (2018). Recuperado em 20 de junho de 2018, de https://www.savefoodbrasil.org/ 
Perdas e desperdícios de alimentos: reflexões sobre o atual cenário brasileiro

Santos, K. L. et al.

Sem Desperdício. (2018). Recuperado em 19 de junho de 2018, de https://www.semdesperdicio.org/

United Nations Educational, Scientific and Cultural Organization - UNESCO. (2006). Declaração Universal sobre Bioética e Direitos Humanos. Portugal. Recuperado em 19 de junho de 2018, de http://unesdoc.unesco.org/images/0014/001461/146180por.pdf

United Nations Environmental Programme - UNEP. (2014). Prevention and reduction of food and drink waste in businesses and households: Guidance for governments, local authorities, businesses and other organisations, Version 1.0. Recuperado em 16 de junho de 2018, de http://www.fao.org/fileadmin/user_upload/save-food/PDF/Guidance-content.pdf

United Nations. Department of Economic and Social Affairs. Population Division. (2017). World population prospects: The 2017 revision, key findings and advance tables. Recuperado em 17 de maio de 2018, de https://esa.un.org/unpd/wpp/

World Resources Institute - WRI. (2017). Annual Meeting 2018: Forum Foundations Report. Recuperado em 12 de junho de 2018, de https://www.weforum.org/reports/world-economic-forum-annual-meeting-2018-forum-foundations-report

Financiamento: CNPq e Coordenação de Aperfeiçoamento de Pessoal de Nível Superior (CAPES). 